\title{
Produtividade e qualidade fisiológica de sementes de feijão em conseqüência da aplicação foliar de manganês
}

\author{
Danilo Silveira Fernandes ${ }^{(1)}$, Rogério Peres Soratto ${ }^{(2)}$, Stela Maris Kulczynski( ${ }^{(1)}$, Guilherme Augusto Biscaro(1) \\ e Cleodir Jorge dos Reis ${ }^{(1)}$
}

\begin{abstract}
(1)Universidade Estadual de Mato Grosso do Sul, Unidade Universitária de Cassilândia, Rod. MS 306, Km 06, Zona Rural, CEP 79540-000 Cassilândia, MS. E-mail: sos_fernandes@yahoo.com.br, stelamk@terra.com.br, gbiscaro@uems.br, cjdosreis@hotmail.com (2)Universidade Estadual Paulista, Fac. de Ciências Agronômicas, Campus de Botucatu, Caixa Postal 237, CEP 18603-970 Botucatu, SP. E-mail: soratto@fca.unesp.br
\end{abstract}

\begin{abstract}
Resumo - O objetivo deste trabalho foi avaliar o efeito de doses e épocas de aplicação de manganês, por via foliar, na produtividade e qualidade fisiológica de sementes do feijoeiro irrigado 'Pérola', cultivado em Neossolo Quatizarênico. O delineamento utilizado foi o de blocos ao acaso, em arranjo fatorial 4x3, com quatro repetições. Os tratamentos constituíram-se de quatro doses de $\mathrm{Mn}\left(0,150,300 \mathrm{e} 600 \mathrm{~g} \mathrm{ha}^{-1}\right)$ aplicadas em três épocas: $\mathrm{R}_{5}$ (pré-florescimento), $\mathrm{R}_{6}$ (florescimento pleno) e divididas metade em $\mathrm{R}_{5}$ e metade em $\mathrm{R}_{6}$. Mesmo em solo com alto teor de $\mathrm{Mn}$, a aplicação via foliar do nutriente aumentou o número de vagens por planta, a massa de 100 sementes e a produtividade de sementes do feijoeiro. Não houve diferença entre o fornecimento de Mn via foliar no pré-florescimento e no florescimento do feijoeiro. A germinação de sementes de feijão não foi afetada pelas aplicações de $\mathrm{Mn}$ via foliar em diferentes épocas e doses. O índice de velocidade de emergência diminuiu com a aplicação de Mn.
\end{abstract}

Termos para indexação: Phaseolus vulgaris, micronutriente, componentes da produção, irrigação, cerrado.

\section{Yield and physiological quality of common bean seeds as affected by manganese foliar application}

\begin{abstract}
The objective of this work was to evaluate the effect of doses and time of manganese leaf application on yield and physiological quality of seeds on irrigated common bean, cultivar Pérola, grown in Typic Quartzipsamment. A randomized block design was used, in a factorial array $4 \mathrm{x} 3$ with four replications. The treatments were constituted by four doses of $\mathrm{Mn}\left(0,150,300\right.$, and $\left.600 \mathrm{~g} \mathrm{ha}^{-1}\right)$ and three application times: $\mathrm{R}_{5}$ (preflowering), $\mathrm{R}_{6}$ (full flowering), and splitted half in $\mathrm{R}_{5}$ and half in $\mathrm{R}_{6}$. Even in $\mathrm{Mn}$ high content soil, the Mn leaf application increased the number of pods per plant, mass of 100 seeds and the seed yield of common bean. There was not difference among Mn leaf application in the pre-flowering and in the flowering stages. Common bean seeds germination was not affected by the time and doses of Mn leaf application. The emergency speed index decreased with Mn application.
\end{abstract}

Index terms: Phaseolus vulgaris, micronutrient, yield components, irrigation, cerrado.

\section{Introdução}

O feijão (Phaseolus vulgaris L.) deixou de ser considerado apenas como cultura de subsistência e passou a ser cultivado no inverno, por médios e grandes produtores que adotam tecnologias avançadas, inclusive a irrigação por aspersão (Yokoyama et al., 1996). Nessa época de cultivo, além da maior produtividade, é possível a colocação do feijão no mercado na entressafra, com menor ocorrência de pragas e doenças e menor incidência de plantas daninhas, o que torna a época interessante para a produção de sementes (Bragantini, 1996), e a cultura em uma das alternativas mais rentáveis para o cultivo irrigado no inverno.
Para Teixeira et al. (2004a), apesar da alta tecnologia adotada pelos produtores no cultivo do feijoeiro irrigado, a nutrição mineral muitas vezes é negligenciada, principalmente em relação aos micronutrientes.

Embora a toxidez de Mn seja comum nos solos brasileiros (Borkert et al., 2001), sintomas de deficiência ocorrem em solos arenosos, de baixa fertilidade natural (Oliveira et al., 1996), principalmente onde há utilização intensiva de técnicas agrícolas que promovam aumento na produtividade das culturas e a retirada crescente do micronutriente sem a adequada reposição e, em casos onde há aplicação excessiva de calcário, o que causa indisponibilização do nutriente para as plantas (Mann et al., 2002). Porém, mesmo em solos ácidos, em que os 
teores de Mn geralmente são elevados, pode ocorrer deficiência do nutriente (Borkert et al., 2001), já que a absorção de Mn pode ser diminuída, entre outros fatores, por altas concentrações de $\mathrm{K}, \mathrm{Ca}, \mathrm{Mg}, \mathrm{Cu}, \mathrm{Zn}, \mathrm{Na}$ e Fe no meio (Fageria, 2001). Rosolem \& Nakagawa (1990) demonstraram que a deficiência de Mn em soja pode ser induzida pela calagem, principalmente quando acompanhada da aplicação de doses relativamente elevadas de potássio. A utilização intensiva de fosfatos no solo também contribui para a baixa disponibilidade do micronutriente (Mascarenhas et al., 1996).

O Mn tem importante papel no metabolismo das plantas, pois atua em processos de ativação de diferentes enzimas, síntese de clorofila e fotossíntese (Fageria, 2001; Taiz \& Zeiger, 2004). Esse nutriente desempenha papel fundamental na elongação celular e sua deficiência pode inibir a síntese de lipídios ou metabólitos secundários, como o ácido giberélico e os isoprenóides (Malavolta et al., 1997). Além disso, o Mn está relacionado à formação da lignina (Marschner, 1995), presente na parede celular, à qual confere menor permeabilidade, exercendo assim, efeito significativo sobre a capacidade e a velocidade de absorção de água através do tegumento das sementes. Segundo Panobianco et al. (1999), sementes com baixo teor de lignina no tegumento apresentam menor vigor, o que pode estar relacionado à deficiência de Mn (Mann et al., 2002; Melarato et al., 2002; Teixeira et al., 2005). Nesse sentido, o fornecimento adequado e equilibrado de nutrientes para o feijoeiro pode contribuir não só para aumentar a produtividade, mas também para melhorar a qualidade fisiológica das sementes produzidas (Teixeira et al., 2004b, 2005).

O feijoeiro, por ser planta de ciclo curto, necessita que os nutrientes estejam prontamente disponíveis nos estádios de maior demanda, para que não haja limitação da produtividade (Silva \& Silveira, 2000). A exigência nutricional da cultura é mais intensa com o início da fase reprodutiva, e é mais crítica na época de formação das sementes, quando consideráveis quantidades de nutrientes são para elas translocadas (Oliveira et al., 1996). Essa maior exigência se deve ao fato de os nutrientes serem essenciais à formação e ao desenvolvimento de novos órgãos de reserva (Carvalho \& Nakagawa, 2000). Assim, a adubação foliar pode ser uma alternativa interessante para o fornecimento de manganês para as culturas no início da fase reprodutiva (Oliveira Júnior et al., 2000; Teixeira et al., 2004b) e pode ser mais eficiente que a aplicação via solo (Lopes \& Souza, 2001; Mann et al., 2001, 2002).
O objetivo deste trabalho foi avaliar o efeito de doses e épocas de aplicação de Mn, por via foliar, na produtividade e qualidade fisiológica de sementes do feijoeiro em cultivo irrigado no inverno, em solo de cerrado.

\section{Material e Métodos}

O trabalho foi realizado na Fazenda Cambuí, Município de Cassilândia, MS $\left(52^{\circ} 37^{\prime} \mathrm{W}, 1^{\circ} 47^{\prime} \mathrm{S}\right.$ e $600 \mathrm{~m}$ de altitude), em área anteriormente cultivada com a sucessão de feijão e pastagem, no ano agrícola 2003/2004. O solo do local é Neossolo Quartzarênico, originalmente sob vegetação de cerrado, cujos resultados de análises química e granulométrica, da camada de 0-20 cm de profundidade, foram: $\mathrm{pH}\left(\mathrm{CaCl}_{2}\right) 5,2$; $25 \mathrm{mg} \mathrm{dm}^{-3}$ de $\mathrm{P}$ (resina); $1,1 \mathrm{mmol}_{\mathrm{c}} \mathrm{dm}^{-3}$ de $\mathrm{K}$ trocável; $15 \mathrm{mmol}_{\mathrm{c}} \mathrm{dm}^{-3}$ de Ca trocável; $7 \mathrm{mmol}_{\mathrm{c}} \mathrm{dm}^{-3} \mathrm{de}$ $\mathrm{Mg}$ trocável; $18 \mathrm{mmol}_{\mathrm{c}} \mathrm{dm}^{-3}$ de $\mathrm{H}+\mathrm{Al}$; saturação por bases (V\%), $56 \% ; 5 \mathrm{mg} \mathrm{dm}^{-3}$ de S; 0,3 $\mathrm{mg} \mathrm{dm}^{-3}$ de B; $0,6 \mathrm{mg} \mathrm{dm}^{-3} \mathrm{de} \mathrm{Cu} ; 0,6 \mathrm{mg} \mathrm{dm}^{-3} \mathrm{de} \mathrm{Cu} ; 10 \mathrm{mg} \mathrm{dm}^{-3} \mathrm{de}$ Fe; $10 \mathrm{mg} \mathrm{dm}^{-3} \mathrm{de} \mathrm{Mn;} 1,2 \mathrm{mg} \mathrm{dm}^{-3} \mathrm{de} \mathrm{Zn;} 28 \mathrm{~g} \mathrm{~kg}^{-1} \mathrm{de}$ matéria orgânica; $835 \mathrm{~g} \mathrm{~kg}^{-1}$ de areia; $81 \mathrm{~g} \mathrm{~kg}^{-1}$ de silte; e $84 \mathrm{~g} \mathrm{~kg}^{-1}$ de argila. $\mathrm{O}$ boro e os demais micronutrientes foram extraídos por $\mathrm{BaCl}_{2}$ e DTPA, respectivamente.

$\mathrm{O}$ solo foi preparado com uma gradagem pesada e duas gradagens leves, a primeira realizada cerca de quinze dias antes da semeadura e a segunda às vésperas da semeadura.

A adubação de semeadura constou da aplicação, em todos os tratamentos, $400 \mathrm{~kg} \mathrm{ha}^{-1}$ da fórmula $\mathrm{N}-\mathrm{P}-\mathrm{K}$ 6-22-12+6,25\% de S. A semeadura do feijoeiro foi realizada mecanicamente em 5/6/2005, com a cultivar Pérola. Foi utilizado espaçamento de 0,45 m entre linhas, e sementes necessárias para se obterem 15-17 plantas por metro. As sementes foram tratadas com carboxim + thiram $(200+200 \mathrm{~g}$ do i.a. por $100 \mathrm{~kg}$ de sementes). A emergência das plantas ocorreu em 11/6/2005.

O delineamento experimental utilizado foi o de blocos ao acaso, no arranjo fatorial $4 \times 3$, com quatro repetições. Os tratamentos foram constituídos pela aplicação de quatro doses de $\mathrm{Mn}\left(0,150,300\right.$ e $\left.600 \mathrm{~g} \mathrm{ha}^{-1}\right)$ e três épocas de aplicação: estádio $\mathrm{R}_{5}$, aos 33 dias após a emergência das plântulas (DAE); estádio $\mathrm{R}_{6}$, aos $44 \mathrm{DAE}$, e metade em $\mathrm{R}_{5}$ e metade em $\mathrm{R}_{6}$, tendo como fonte o produto comercial quelatizado Mangan 10 (10\% de $\mathrm{Mn}$ e densidade de 1,32 $\mathrm{g} \mathrm{mL}^{-1}$ ), em pulverização foliar com vazão de $200 \mathrm{~L} \mathrm{ha}^{-1}$ de calda. De acordo com Fernández et al. (1986), no estádio $\mathrm{R}_{5}$, as plantas de feijão se encontram na pré-floração (botões florais) e 
em $\mathrm{R}_{6}$ no florescimento pleno ( $50 \%$ da plantas com flores abertas). Cada parcela foi constituída por cinco linhas de $6 \mathrm{~m}$ de comprimento. A área útil foi constituída pelas três linhas centrais, tendo-se desprezado $0,50 \mathrm{~m}$ em ambas as extremidades de cada linha.

As adubações de cobertura foram realizadas via pivô central, com a aplicação de $140 \mathrm{~kg} \mathrm{ha}^{-1}$ da fórmula $\mathrm{N}-\mathrm{P}-\mathrm{K} 25-0-15+8,5 \%$ de $\mathrm{S}$, aos 20 DAE e $240 \mathrm{~kg} \mathrm{ha}^{-1}$ da fórmula N-P-K $16-0-32+5,0 \%$ de S aos 30 DAE.

O controle de plantas daninhas foi realizado com os herbicidas seletivos bentazon (720 g do i.a. ha-1) e fluazifop-p-butil (200 g do i.a. por ha), recomendados para a cultura do feijão.

A irrigação foi realizada durante todo o ciclo da cultura por meio de aspersão com um pivô central dotado de difusores. O manejo da irrigação foi realizado por meio de balanço hídrico, e foi utilizada uma estação meteorológica automatizada para fornecimento das informações de evapotranspiração diária e precipitação, necessárias para o cálculo do balanço.

Durante o desenvolvimento da cultura, foram realizados os demais tratos culturais e fitossanitários recomendados.

$\mathrm{Na}$ área útil de cada parcela, foram avaliados os componentes da produção: número de vagens por planta, número médio de sementes por vagem, massa de 100 sementes e produção de sementes, foi feita a pesagem das sementes obtidas na área útil de cada parcela e os dados foram transformados em $\mathrm{kg} \mathrm{ha}^{-1}$ (13\% base úmida).

Seis meses após a colheita, as sementes foram avaliadas quanto: à germinação; à primeira contagem de germinação; à de emergência em campo; ao índice de velocidade de emergência; à condutividade elétrica; e à massa seca da parte aérea das plântulas. A germinação foi realizada com uma subamostra de 50 sementes de cada parcela, colocadas eqüidistantemente em rolos de papel germitest umedecido com água deionizada, em quantidade equivalente a 2,5 vezes o seu peso, e mantidas em germinador à temperatura de $25^{\circ} \mathrm{C}$. As contagens foram realizadas aos 5 e 9 dias após a montagem do teste, para se indicar a porcentagem de plântulas normais (Brasil, 1992). A primeira contagem de germinação foi realizada em conjunto com o teste de germinação, tendo-se computado as porcentagens de plântulas normais verificadas no quinto dia após a montagem.

No teste de emergência em campo foram semeadas 50 sementes de cada parcela, distribuídas em sulcos de $2 \mathrm{~m}$ de comprimento e $2 \mathrm{~cm}$ de profundidade, tendo-se mantido as sementes equiidistantes. Os sulcos foram espaçados de $20 \mathrm{~cm}$, e as contagens foram realizadas aos 21 dias após a semeadura, tendo-se computado as plântulas com os cotilédones acima da superfície do solo e com as folhas simples com as margens sem se tocar.

$O$ índice de velocidade de emergência (IVE) foi determinado em conjunto com o teste de emergência de plântulas em campo, tendo-se anotado, diariamente, no mesmo horário, o número de plântulas que apresentavam as folhas embrionárias visíveis. Ao final do teste, com os dados diários do número de plântulas normais, calculou-se o IVE com a fórmula proposta por Maguire (1962).

Para a determinação da condutividade elétrica, utilizou-se uma subamostra de 50 sementes de cada parcela, pesadas e colocadas em um recipiente com $75 \mathrm{~mL}$ de água destilada e mantidas durante 24 horas em germinador a $25^{\circ} \mathrm{C}$. Após esse período, foi feita a leitura dos exsudatos liberados na água, com o auxílio do condutivímetro, modelo Marconi CA-150, e o valor foi expresso em $\mu \mathrm{S} \mathrm{cm}^{-1} \mathrm{~g}^{-1}$ (Vieira \& Krzyzanowski, 1999).

A massa de matéria seca da parte aérea das plântulas foi obtida com o teste instalado para avaliação da emergência de plântulas no campo. Após 21 dias da semeadura, 25 plântulas foram arrancadas, e tiveram a parte aérea separada do sistema radicular. Foram então colocadas em saco de papel e levadas para estufa com circulação de ar forçado, mantida à temperatura de $65^{\circ} \mathrm{C}$, até peso constante. Foram utilizadas quatro repetições por tratamento.

Os resultados foram submetidos à análise de variância. Os efeitos das doses foram avaliados pela análise de regressão, tendo-se adotado como critério para escolha do modelo a magnitude dos coeficientes de regressão significativos a $5 \%$ de probabilidade pelo teste F. Foram realizadas análises de correlação simples entre os componentes da produção e a produtividade de sementes do feijoeiro, a fim de se determinar o grau de associação entre essas variáveis.

\section{Resultados e Discussão}

O florescimento pleno da cultura ocorreu aos $44 \mathrm{DAE}$, e o ciclo teve a duração de 89 dias em todos os tratamentos.

Os componentes da produção, a produtividade e a qualidade fisiológica das sementes de feijão não foram influenciados pelas épocas de aplicação de Mn via foliar (Tabela 1). Também não foi constatado efeito 
significativo da interação entre os fatores dose e época de aplicação de Mn sobre nenhuma das variáveis analisadas. É importante mencionar que houve boa precisão experimental, indicada pelos baixos valores de coeficientes de variação.

Pela Tabela 1 e Figura 1, verifica-se que a aplicação de Mn via foliar proporcionou aumento do número de vagens por planta até a dose máxima estimada de $258 \mathrm{~g} \mathrm{ha}^{-1}$, com um valor máximo de 15,97 vagens por planta, e que foi $7 \%$ maior que o valor do tratamento testemunha (sem aplicação de Mn). Ao trabalhar com soja, Oliveira Júnior et al. (2000) e Mann et al. (2001) observaram que com a aplicação de Mn via foliar houve maior número de vagens por planta em relação à testemunha, o que sugeria menor abortamento de flores e vagens. Teixeira et al. (2004b) também observaram aumento do número de vagens por planta do feijoeiro, cultivar Pérola, em consequiência da aplicação de $\mathrm{Mn}$ via foliar aos 25 e $35 \mathrm{DAE}$, na dose de $340 \mathrm{~g} \mathrm{ha}^{-1}$, com aumento de $22 \%$ em relação à testemunha. No entanto, conforme relatado por esses autores, a aplicação de elevadas doses de Mn causou redução no número de vagens por planta, o que pode indicar efeito fitotóxico do nutriente em doses elevadas.

O número de sementes por vagem não foi afetado pela aplicação de Mn via foliar (Tabela 1), pois é uma característica de alta herdabilidade genética, que sofre pouca influência do ambiente (Andrade et al., 1998), com valor médio de 4,4 grãos por vagem. No entanto, os resultados são contraditórios aos observados por Teixeira et al. (2004b), que verificaram aumento no valor dessa variável com a aplicação de Mn via foliar no feijoeiro.

A massa de 100 sementes sofreu influência linear da aplicação de doses crescentes de Mn via foliar (Tabela 1 e Figura 1). A elevação da dose de Mn aumentou o valor dessa variável até a dose máxima estudada, e com a aplicação de $600 \mathrm{~g} \mathrm{ha}^{-1}$ de $\mathrm{Mn}$ obteveram-se sementes $8,8 \%$ mais pesadas que no tratamento testemunha. Tal resultado pode ser explicado pelo papel que esse nutriente desempenha em rotas bioquímicas que garantem a formação de lipídeos, proteínas e ainda contribuem na estruturação das membranas celulares (Malavolta et al., 1997). Esses dados concordam com Mann et al. (2001) e Melarato et al. (2002), que verificaram aumento na massa de sementes de soja com a aplicação de manganês, tanto via foliar quanto via solo, em relação à testemunha. Esse fato apresenta relevância no aspecto qualitativo, tendose em vista a possibilidade de as sementes que receberam manganês apresenta um conteúdo de reserva maior. Contudo, Teixeira et al. (2004b) não obtiveram aumento na massa de sementes de feijão, cultivado em solo de cerrado, mediante a aplicação de Mn via foliar.

A produtividade de sementes de feijão foi afetada pela dose de Mn aplicada (Tabela 1), com os dados ajustados à função quadrática (Figura 1). A dose de $416 \mathrm{~g} \mathrm{ha}^{-1} \mathrm{de}$ $\mathrm{Mn}$ proporcionou a maior eficiência técnica, com aumento na produtividade de $376,5 \mathrm{~kg} \mathrm{ha}^{-1}$, ou seja, $11 \%$ em relação à testemunha (sem aplicação de Mn). Mann et al. (2002) também verificaram efeito positivo da aplicação de $\mathrm{Mn}$ foliar na produtividade da soja. Teixeira et al. (2004) estudaram a interação de doses crescentes de $\mathrm{Zn}$ e $\mathrm{Mn}$, via foliar, no feijoeiro e observaram que a dose de $315 \mathrm{~g} \mathrm{ha}^{-1}$ de $\mathrm{Mn}$, associada a $280 \mathrm{~g} \mathrm{ha}^{-1} \mathrm{de} \mathrm{Zn}$, alcançou a máxima eficiência técnica, em duas aplicações foliares aos 25 e 35 DAE, e correspondeu à produção máxima estimada de $2.275 \mathrm{~kg} \mathrm{ha}^{-1}$ de grãos. Este aumento de produtividade de sementes, em conseqüência da aplicação de Mn foliar, se deve ao fato de que esse elemento tem importantes funções na planta, destacando-se na participação da fotossíntese e no metabolismo do $\mathrm{N}$ e, também, nos compostos cíclicos

Tabela 1. Análise de variância para os componentes da produção do feijoeiro, cultivar Pérola, e para variáveis relacionadas à qualidade fisiológica das sementes, em função das doses e épocas de aplicação foliar de manganês.

\begin{tabular}{|c|c|c|c|c|c|c|}
\hline \multirow[t]{2}{*}{ Variável analisada } & \multicolumn{5}{|c|}{ Valor de $\mathrm{F}^{(1)}$} & \multirow[t]{2}{*}{$\mathrm{CV}(\%)$} \\
\hline & Dose (D) & Época (E) & DxE & $\mathrm{RL}_{\text {Dose }}$ & $\mathrm{RQ}_{\text {Dose }}$ & \\
\hline Número de vagens por planta & $3,97 *$ & $0,09^{\text {ns }}$ & $0,64^{\mathrm{ns}}$ & $1,47^{\mathrm{ns}}$ & $4,24 *$ & 13,3 \\
\hline Número de sementes por vagem & $0,367^{\mathrm{ns}}$ & $0,19^{\text {ns }}$ & $1,02^{\mathrm{ns}}$ & $0,44^{\mathrm{ns}}$ & $0,46^{\mathrm{ns}}$ & 5,4 \\
\hline Massa de 100 sementes (g) & $11,67 * *$ & $0,61^{\mathrm{ns}}$ & $1,28^{\mathrm{ns}}$ & $31,36 * *$ & $0,68^{\mathrm{ns}}$ & 4,3 \\
\hline Produtividade de sementes $\left(\mathrm{kg} \mathrm{ha}^{-1}\right)$ & $5,46^{* *}$ & $0,44^{\mathrm{ns}}$ & $0,43^{\mathrm{ns}}$ & $9,33 * *$ & $6,99 *$ & 6,4 \\
\hline Germinação (\%) & $1,64^{\mathrm{ns}}$ & $0,47^{\text {ns }}$ & $0,47^{\mathrm{ns}}$ & $0,88^{\text {ns }}$ & $0,80^{\mathrm{ns}}$ & 1,9 \\
\hline Primeira contagem $(\%)$ & $0,76^{\mathrm{ns}}$ & $0,56^{\mathrm{ns}}$ & $1,25^{\mathrm{ns}}$ & $0,31^{\mathrm{ns}}$ & $1,61^{\mathrm{ns}}$ & 5,5 \\
\hline Emergência em campo (\%) & $1,83^{\mathrm{ns}}$ & $0,20^{\mathrm{ns}}$ & $0,33^{\mathrm{ns}}$ & $0,27^{\mathrm{ns}}$ & $1,72^{\mathrm{ns}}$ & 2,9 \\
\hline Índice de velocidade de emergência & $8,22 * *$ & $0,20^{\text {ns }}$ & $0,34^{\mathrm{ns}}$ & $18,88 * *$ & $2,64^{\mathrm{ns}}$ & 5,8 \\
\hline Condutividade elétrica $\left(\mu \mathrm{S} \mathrm{cm}^{-1} \mathrm{~g}^{-1}\right)$ & $0,28^{\text {ns }}$ & $0,73^{\text {ns }}$ & $0,48^{\mathrm{ns}}$ & $0,51^{\mathrm{ns}}$ & $0,32^{\text {ns }}$ & 6,8 \\
\hline Massa de matéria seca (g plântula ${ }^{-1}$ ) & $0,81^{\mathrm{ns}}$ & $0,46^{\mathrm{ns}}$ & $1,29^{\text {ns }}$ & $0,43^{\mathrm{ns}}$ & $1,92^{\mathrm{ns}}$ & 7,3 \\
\hline
\end{tabular}

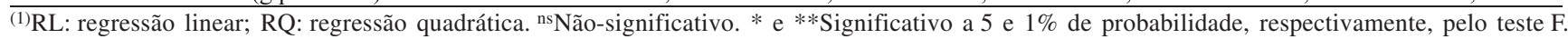



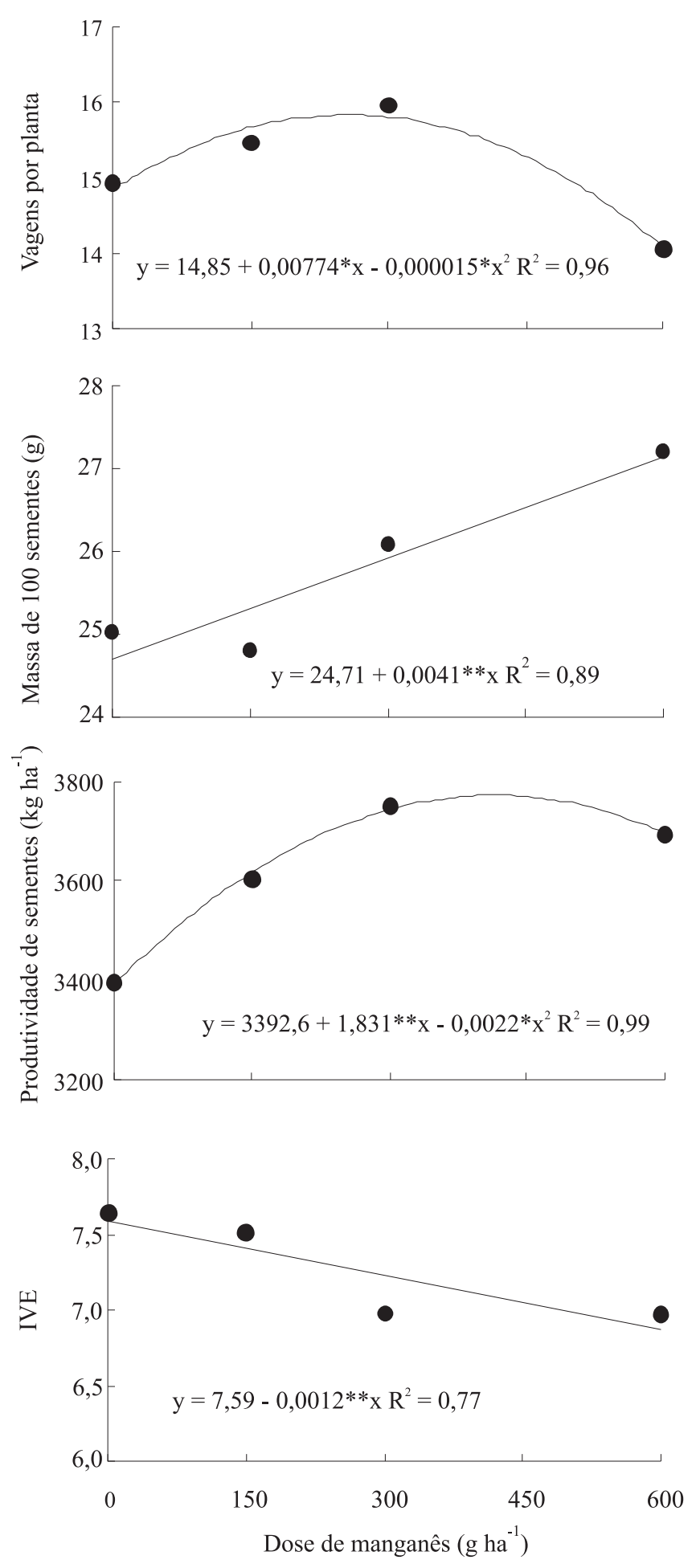

Figura 1. Número de vagens por planta, massa de 100 sementes, produtividade e índice de velocidade de emergência (IVE) de sementes de feijão, em função da aplicação de doses de manganês via foliar. Média de três épocas de aplicação. * e **Significativo a 5 e $1 \%$ de probabilidade, respectivamente, pelo teste t. como precursor de aminoácidos aromáticos, hormônios, fenóis e ligninas (Heenan \& Campbell, 1980).

$\mathrm{O}$ aumento da produtividade foi reflexo, principalmente, do acréscimo proporcionado pela aplicação de $\mathrm{Mn}$ foliar na massa de 100 sementes, já que somente esse componente da produção se correlacionou significativamente $(\mathrm{r}=0,32 *)$ com a produtividade.

É importante destacar que, mesmo com teor elevado de Mn no solo, é possível aumentar a produtividade do feijoeiro cultivado com alto nível de tecnologia, mediante a aplicação de Mn via foliar, nos estádios de préflorescimento $\left(\mathrm{R}_{5}\right)$ e florescimento $\left(\mathrm{R}_{6}\right)$. Tais resultados podem ser explicados pelo fato de que a disponibilidade de Mn às plantas é dependente de diversos fatores, como: $\mathrm{pH}$, potencial de oxi-redução, matéria orgânica e equilíbrio com outros cátions, principalmente o ferro, cálcio e magnésio (Borkert et al., 2001; Fageria, 2001). Assim, altas doses de calcário ou potássio podem limitar o desenvolvimento da planta, por provocar deficiência de Mn (Rosolem \& Nakagawa, 1990), o que pode ter ocorrido neste trabalho, já que o teor de Ca no solo encontrava-se em uma faixa considerada alta (Raij et al., 1996) e, durante o desenvolvimento da cultura, foram aplicados $145,8 \mathrm{~kg} \mathrm{ha}^{-1}$ de $\mathrm{K}_{2} \mathrm{O}$. Além disso, existem diferenças entre cultivares de feijão no que se refere à absorção de Mn do solo. Soratto et al. (2005) verificaram que plantas de feijão 'Pérola' apresentam, em média, menores teores e acúmulo de Mn, quando comparadas às de outras cultivares (Carioca, IAC Carioca Eté e FT Bonito), o que pode ser um indicativo de que essa cultivar apresenta menor eficiência na absorção do elemento via sistema radicular.

A disponibilidade de nutrientes influencia a formação do embrião e dos cotilédones, com resultados eficazes sobre o vigor e a qualidade fisiológica das sementes (Teixeira et al., 2005). No entanto, neste trabalho não foi observado efeito dos tratamentos na germinação das sementes (Tabela 1), o que concorda com os resultados obtidos com soja por Mann et al. (2002) e Melarato et al. (2002), e com feijão no inverno por Teixeira et al. (2005). O valor médio para o teste de germinação foi de $99 \%$, portanto, bem acima do padrão mínimo para comercialização de sementes de feijão no Brasil, que atualmente é de $80 \%$ (Brasil, 1992).

A questão do vigor é de extrema importância, pois de acordo com Krzyzanowski et al. (1991), sementes com baixo vigor, mesmo com alta porcentagem de germinação, podem resultar em prejuízos aos agricultores, quando submetidas a condições 
desfavoráveis de campo, principalmente pelo estabelecimento inadequado do estande. $\mathrm{O}$ vigor das sementes, avaliado pelos testes de primeira contagem e emergência em campo, também não foi influenciado pela aplicação de Mn via foliar (Tabela 1), com média de 97\% de emergência de plântulas.

$\mathrm{Na}$ avaliação do vigor por meio do IVE, observou-se que a aplicação de manganês foliar proporcionou decréscimo linear dos valores, o que indica diminuição na velocidade de emergência das plântulas, com o aumento da dose de Mn foliar aplicada (Figura 1). A aplicação da maior dose de Mn proporcionou uma redução de $9,5 \%$ no IVE em relação à testemunha. Uma explicação para isso seria o fato de que o manganês está envolvido na formação da lignina, uma das substâncias presentes na parede celular e que apresenta características de impermeabilização e pode exercer efeito significativo sobre a capacidade e a velocidade de absorção de água através do tegumento (Panobianco et al., 1999) e alterar, desse modo, a velocidade de emergência das sementes. Além disso, a maior massa de 100 sementes pode ter contribuído para a emergência mais lenta das sementes provenientes dos tratamentos em que foram aplicadas as maiores doses de Mn, já que houve correlação negativa $\left(r=-0,37^{*}\right)$ entre a massa de 100 sementes e o IVE. Lima et al. (2002) e Crusciol et al. (2003) também verificaram menor índice de velocidade de germinação, em sementes de feijão com maior massa.

No teste de condutividade elétrica não se constatou efeito dos tratamentos (Tabela 1), com valor médio de $57,4 \mu \mathrm{S} \mathrm{cm}^{-1} \mathrm{~g}^{-1}$. Esse resultado discorda dos obtidos por Teixeira et al. (2005), que verificaram redução nos valores de condutividade elétrica no extrato de sementes de feijão, mediante a aplicação de Mn via foliar. Entretanto, vale destacar que os valores obtidos neste experimento foram menores que os observados por esses autores. Geralmente, valores maiores de condutividade elétrica são ocasionados pela maior liberação de exsudatos no meio, em virtude do comprometimento da integridade das membranas, e estão relacionados a sementes de qualidade inferior (Vieira \& Krzyzanovski, 1999). Como já mencionado, o Mn está envolvido na formação da lignina no tegumento e pode reduzir a quantidade de lixiviados liberados para o meio externo (Panobianco et al., 1999).

Plantas provenientes de sementes de alto vigor apresentam desempenho inicial superior àquelas oriundas de sementes de baixo vigor, e influenciam, inclusive, a produtividade (Sá, 1994). Dessa forma, é de extrema importância a capacidade de emergência das sementes no campo e o vigor do desenvolvimento inicial, para se assegurar adequado estabelecimento e estande da cultura, características que são influenciadas pelo estado nutricional da planta (Carvalho \& Nakagawa, 2000; Teixeira et al., 2005). No entanto, a massa de matéria seca de parte aérea de plântulas de feijão não foi afetada pelas doses e épocas de aplicação de Mn via foliar (Tabela 1).

Embora tenha influenciado alguns componentes da produção e produtividade de sementes, a adubação foliar com Mn não afetou de maneira relevante a qualidade fisiológica das sementes de feijão, o que pode estar associado ao alto teor de $\mathrm{Mn}$ no solo $\left(10 \mathrm{mg} \mathrm{dm}^{-3}\right)$ que, apesar de não ter sido suficiente para obtenção de máxima produtividade, pode não ter limitado a adequada formação das sementes. Mann et al. (2002) e Teixeira et al. (2005) também verificaram efeito mais expressivo da aplicação foliar de Mn na produtividade do que na qualidade das sementes de soja e feijão, respectivamente.

\section{Conclusões}

1. A aplicação de manganês via foliar aumenta o número de vagens por planta, a massa de 100 sementes e a produtividade de grãos do feijoeiro irrigado, mesmo em solo com alto teor desse nutriente.

2. Não há diferença entre o fornecimento de manganês via foliar no pré-florescimento ou no florescimento do feijoeiro.

3. A germinação de sementes de feijão não é afetada pelas épocas e doses de manganês via foliar, em solo com alto teor desse nutriente.

4. O índice de velocidade de emergência sofre efeito negativo com a aplicação via foliar de manganês.

\section{Agradecimentos}

À Sra. Luciana Carvalho Dias, Fazenda Camboí, por ter cedido a área para a condução do trabalho.

\section{Referências}

ANDRADE, M.J.B. de; DINIZ, A.R.; CARVALHO, J.G. de; LIMA, S.F. de. Resposta da cultura do feijoeiro à aplicação foliar de molibdênio e às adubações nitrogenadas de plantio e cobertura. Ciência e Agrotecnologia, v.22, p.499-508, 1998. 
BORKERT, C.M.; PAVAN, M.A.; BATAGLIA, O.C. Disponibilidade e avaliação de elementos catiônicos: ferro e manganês. In: FERREIRA, M.E.; CRUZ, M.C.P. da; RAIJ, B. van; ABREU, C.A. de. Micronutrientes e elementos tóxicos na agricultura. Jaboticabal: CNPq/Fapesp/Potafos, 2001. p.151-185.

BRAGANTINI, C. Produção de sementes. In: ARAÚJO, R.S.; RAVA, C.A.; STONE, L.F.; ZIMMERMANN, M.J.O. (Coord.). Cultura do feijoeiro comum no Brasil. Piracicaba: Potafos, 1996. p.639-667.

BRASIL. Ministério da Agricultura, Pecuária e Abastecimento. Regras para análise de sementes. Brasília: SNAD/DNPV/CLAV, 1992. 365p.

CARVAlHO, N.M.; NAKAGAWA, J. Sementes: ciência, tecnologia e produção. 4.ed. Jaboticabal: Funep, 2000. 588p.

CRUSCIOL, C.A.C.; LIMA, E. do V.; ANDREOTTI, M.; NAKAGAWA, J.; LEMOS, L.B.; MARUBAYASHI, O.M. Efeito do nitrogênio sobre a qualidade fisiológica, produtividade e características de sementes de feijão. Revista Brasileira de Sementes, v.25, p.108-115, 2003.

FAGERIA, V.D. Nutrient interactions in crop plants. Journal of Plant Nutrition, v.24, p.1269-1290, 2001.

FERNÁNDEZ, F.; GEPTS, P.; LÓPES, M. Etapas de desarrollo de la planta de frijol (Phaseolus vulgaris L.). Cali: Centro Internacional de Agricultura Tropical, 1986. 34p.

HEENAN, D.P.; CAMPBELL, L.C. Soybean nitrate reductaseactivity influenced by manganese nutrition. Plant and Cell Physiology, v.21, p.731-736, 1980.

KRZYZANOWSKI, F.C.; FRANÇA NETO, J. de B.; HENNING, A.A. Relato dos testes de vigor disponíveis para as grandes culturas. Informativo Abrates, v.1, p.15-50, 1991.

LIMA, J.S.S.; MARTINS FILHO, S.; LOPES, J.C.; GARCIA, G.O.; SCHIMIDT NETO, R. Qualidade fisiológica de sementes de feijão produzidas em solo compactado. Revista Brasileira de Sementes, v.24, p.111-117, 2002.

LOPES, A.S.; SOUZA, E.C.A. de. Filosofias e eficiência de aplicação. In: FERREIRA, M.E.; CRUZ, M.C.P. da; RAIJ, B. van; ABREU, C.A. de. Micronutrientes e elementos tóxicos na agricultura. Jaboticabal: CNPq/Fapesp/Potafos, 2001. p.255-282.

MAGUIRE, J.D. Speed of germination-aid in selection and evaluation for seedling emergence and vigor. Crop Science, v.2, p.176-177, 1962.

MALAVOLTA, E.; VITTI, G.C.; OLIVEIRA, S.A. Avaliação do estado nutricional das plantas: princípios e aplicações. Piracicaba: Potafos, 1997. 319p.

MANN, E.N.; REZENDE, P.M. de; CARVALHO, J.G. de; CORRÊA, J.B.D. Efeito da adubação com manganês, via solo e foliar em diferentes épocas na cultura da soja (Glycine max (L.) Merrill). Ciência e Agrotecnologia, v.25, p.264-273, 2001.

MANN, E.N.; REZENDE, P.M. de; MANN, R.S.; CARVALHO, J.G. de; PINHO, E.V.R. von. Efeito da aplicação de manganês no rendimento e na qualidade de sementes de soja. Pesquisa Agropecuária Brasileira, v.37, p.1757-1764, 2002.

MARSCHNER, H. Mineral nutrition of higher plants. $2^{\text {nd }} e d$. San Diego: Academic Press, 1995. 889p.

MASCARENHAS, H.A.A.; TANAKA, R.T.; GALLO, P.B.; PEREIRA, J.C.V.N.A.; AMBROSANO, G.M.B.; CARMELLO, Q.A.C. Efeito da calagem sobre a produtividade de grãos, óleo e proteína em cultivares precoces de soja. Scientia Agricola, v.53, p.164-172, 1996.

MELARATO, M.; PANOBIANCO, M.; VITTI, G.C.; VIEIRA, R.D. Manganês e potencial fisiológico de sementes de soja. Ciência Rural, v.32, p.1069-1071, 2002.

OLIVEIRA, I.P.; ARAÚJO, R.S.; DUTRA, L.G. Nutrição mineral e fixação biológica de nitrogênio. In: ARAÚJO, R.S.; RAVA, C.A.; STONE, L.F.; ZIMMERMANN, M.J.O. (Coord.). Cultura do feijoeiro comum no Brasil. Piracicaba: Potafos, 1996. p.169-221. OLIVEIRA JÚNIOR, J.A. de; MALAVOLTA, E.; CABRAL, C.P. Efeitos do manganês sobre a soja cultivada em solo de cerrado do Triângulo Mineiro. Pesquisa Agropecuária Brasileira, v.35, p.1629-1636, 2000.

PANOBIANCO, M.; VIEIRA, R.D.; KRZYZANOWSKI, F.C.; FRANÇA NETO, J.B.F. Electrical conductivity of soybean seed and correlation with seed coat lignin content. Seed Science and Technology, v.27, p.945-949, 1999.

RAIJ, B. van; CANTARELLA, H.; QUAGGIO, J.A.; FURLANI, A.M.C. Recomendações de adubação e calagem para o Estado de São Paulo. Campinas: Instituto Agronômico/Fundag, 1996. 285p. (Boletim técnico, 100).

ROSOLEM, C.A.; NAKAGAWA, J. Deficiência de manganês em soja induzida por adubação potássica e calagem. Pesquisa Agropecuária Brasileira, v.25, p.833-836, 1990.

SÁ, M.E. de. Importância da adubação na qualidade de semente. In: SÁ, M.E. de; BUZZETI, S. (Ed.). Importância da adubação na qualidade dos produtos agrícolas. São Paulo: Ícone, 1994. p.6598.

SILVA, C.C.; SILVEIRA, P.M. da. Influência de sistemas agrícolas na resposta do feijoeiro (Phaseolus vulgaris L.) irrigado à adubação nitrogenada de cobertura. Pesquisa Agropecuária Tropical, v.30, p.86-96, 2000.

SORATTO, R.P.; SILVA, T.R.B. da; BORGHI, E.; SILVA, L.M. da; ROSOLEM, C.A. Resposta de quatro cultivares de feijão ao manganês em solução nutritiva. Revista Brasileira de Agrociência, v.11, p.235-240, 2005.

TAIZ, L.; ZEIGER, E. Fisiologia vegetal. 3.ed. Porto Alegre: Artmed, 2004. 719p.

TEIXEIRA, I.R.; BORÉM, A.; ANDRADE, M.J.B. de; GIÚDICE, M.P.D.; CECON, P.R. Teores de clorofila em plantas de feijoeiros influenciadas pela adubação com manganês e zinco. Acta Scientiarum: Agronomy, v.26, p.147-152, 2004a. 
TEIXEIRA, I.R.; BORÉM, A.; ARAÚJO, G.A. de A.; ANDRADE, M.J.B. de. Teores de nutrientes e qualidade fisiológica de sementes de feijão em resposta à adubação foliar com manganês e zinco. Bragantia, v.64, p.83-88, 2005.

TEIXEIRA, I.R.; BORÉM, A.; ARAÚJO, G.A.A.; FONTES, R.L.F. Manganese and zinc leaf application on common bean grown on a "cerrado" soil. Scientia Agricola, v.61, p.77-81, 2004b.
VIEIRA, R.D.; KRZYZANOWSKI, F.C. Teste de condutividade elétrica. In: KRZYZANOWSKI, F.C.; VIEIRA, R.D.; FRANÇA NETO, J.B.F. Vigor de sementes: conceitos e testes. Londrina: Abrates, 1999. p.1-26.

YOKOYAMA, L.P.; BANNO, K.; KLUTHCOUSKI, J. Aspectos econômicos da cultura. In: ARAUUJO, R.S.; RAVA, C.A.; STONE, L.F.; ZIMMERMANN, M.J.O. (Coord.). Cultura do feijoeiro comum no Brasil. Piracicaba: Potafos, 1996. p.1-21.

Recebido em 11 de setembro de 2006 e aprovado em 14 de dezembro de 2006 